\title{
High resolution 3-D temperature and salinity fields derived from in situ and satellite observations
}

\author{
S. Guinehut ${ }^{1}$, A.-L. Dhomps ${ }^{2}$, G. Larnicol ${ }^{1}$, and P.-Y. Le Traon ${ }^{3}$ \\ ${ }^{1}$ CLS-Space Oceanography Division, Ramonville Saint-Agne, France \\ ${ }^{2}$ LEGOS, Toulouse, France \\ ${ }^{3}$ IFREMER, Plouzané, France \\ Correspondence to: S. Guinehut (sguinehut@cls.fr)
}

Received: 28 February 2012 - Published in Ocean Sci. Discuss.: 22 March 2012

Revised: 4 September 2012 - Accepted: 7 September 2012 - Published: 9 October 2012

\begin{abstract}
This paper describes an observation-based approach that efficiently combines the main components of the global ocean observing system using statistical methods. Accurate but sparse in situ temperature and salinity profiles (mainly from Argo for the last $10 \mathrm{yr}$ ) are merged with the lower accuracy but high-resolution synthetic data derived from satellite altimeter and sea surface temperature observations to provide global 3-D temperature and salinity fields at high temporal and spatial resolution. The first step of the method consists in deriving synthetic temperature fields from altimeter and sea surface temperature observations, and salinity fields from altimeter observations, through multiple/simple linear regression methods. The second step of the method consists in combining the synthetic fields with in situ temperature and salinity profiles using an optimal interpolation method. Results show the revolutionary nature of the Argo observing system. Argo observations now allow a global description of the statistical relationships that exist between surface and subsurface fields needed for step 1 of the method, and can constrain the large-scale temperature and mainly salinity fields during step 2 of the method. Compared to the use of climatological estimates, results indicate that up to $50 \%$ of the variance of the temperature fields can be reconstructed from altimeter and sea surface temperature observations and a statistical method. For salinity, only about 20 to $30 \%$ of the signal can be reconstructed from altimeter observations, making the in situ observing system essential for salinity estimates. The in situ observations (step 2 of the method) further reduce the differences between the gridded products and the observations by up to $20 \%$ for the temperature field in the mixed layer, and the main contribution is for
\end{abstract}

salinity and the near surface layer with an improvement up to $30 \%$. Compared to estimates derived using in situ observations only, the merged fields provide a better reconstruction of the high resolution temperature and salinity fields. This also holds for the large-scale and low-frequency fields thanks to a better reduction of the aliasing due to the mesoscale variability. Contribution of the merged fields is then illustrated to describe qualitatively the temperature variability patterns for the period from 1993 to 2009.

\section{Introduction}

Via the Global Monitoring for Environment and Security program (GMES) and its Marine Core Service Fast Track program, the European community is consolidating past efforts in pre-operational ocean monitoring and forecasting capacity by setting up the MyOcean project (http://www. myocean.eu). This project has developed an integrated system based on observations organized as Thematic Assembly Centers (TAC) and Monitoring and Forecasting Centers (MFC) (Ocean Science, this issue). Whereas TACs are organized by ocean variables (sea level, SST, sea ice, ocean color, in situ temperature and salinity profiles, etc.), the MFCs are organized by regions that cover not only the European seas (Black, Mediterranean, Baltic and Arctic seas, North West Shelf and the Bay of Biscay) but also the Global Ocean. Two components have been developed as part of the Global Ocean MFC led by the French Operational Oceanography Mercator Océan project: a model/assimilation component and an observation-based one that provides Global Ocean 
Observation-based Products (GOOP). The latter generates global 3-D thermohaline and geostrophic current fields using satellite and in situ measurements.

Despite the impressive increase in the number of temperature and salinity profiles from the Argo array (the 3000 floats target was reached in November 2007; Roemmich et al., 2009), in situ data still strongly undersample the ocean thermohaline variability. Global 3-D thermohaline analysis from in situ observations is only possible at large-scale and low-frequency resolution (see for ex. Roemmich and Gilson, 2009; von Schuckmann et al., 2009; among others). In contrast, remote-sensing measurements have provided synoptic observations of sea level and sea surface temperature (SST) over the world's oceans since 1993, but with no direct estimate of the ocean's interior structure. Many studies have used satellite data to complement subsurface observations either at regional or global scales and using different techniques such as multivariate linear regression or gravest empirical modes. These include the works of Fox et al. (2002), Willis et al. (2003), Swart et al. (2010) and Meijers et al. (2011), to name only a few.

In order to reconstruct instantaneous temperature $(T)$ and salinity $(S)$ fields at high temporal and spatial resolution, a merging method is developed here to improve a climatological first guess. It combines the accurate but sparse in situ $T / S$ profiles with the high-resolution but less accurate (as synthetic $T / S$ fields) altimeter and SST measurements. This is only possible since, on the one hand, sea level anomalies (SLA) from altimeter measurements and dynamic height anomalies (DHA) calculated from in situ $T$ and $S$ profiles are strongly correlated (Gilson et al., 1998; McCarthy et al., 2000; Guinehut et al., 2006; Dhomps et al., 2011), and, on the other hand, satellite SST observations can additionally be used to constrain the thermal structure of the ocean in the first hundred meters depth.

The merging method was first developed using simulated datasets (Guinehut et al., 2004) and then using real observations but at regional scale (Larnicol et al., 2006). It has two main steps. The first step consists in deriving synthetic $T$ fields from the surface down to $1500 \mathrm{~m}$ depth from altimeter and SST observations through a multiple linear regression method and covariances calculated from historical data. Synthetic $S$ fields are derived in a very similar way but using a simple linear regression method of altimeter observations. The second step consists in combining the synthetic field with in situ $T$ and $S$ profiles using an optimal interpolation method. The global 3-D thermohaline fields are computed in near real time on a $1 / 3^{\circ}$ Mercator horizontal grid, every 7 days (Wednesday-only fields) and from the surface down to $1500 \mathrm{~m}$ depth on 24 vertical levels. The method has been applied to the period from 1993 to 2009 .

The primary goal of the paper is to demonstrate that the main components of the global ocean observing system can be integrated efficiently using statistical methods. There are two specific objectives. The first is to provide a global de- scription of statistical relationships between surface and subsurface fields using in situ observations only. The second is to quantify the ability of such relationships to reconstruct the interannual variability of the 3-D Ocean thermohaline fields together with additional in situ observations.

The paper is organized as follows. All datasets used in the study are presented in Sect. 2. The 3-D thermohaline fields computed from satellite observations are then described in Sect. 3. Section 4 presents the combination with the in situ profiles. The interannual variability reconstructed by the thermohaline fields is then analyzed in Sect. 5 before the conclusions.

\section{Data}

Three sources of ocean observations are used in our study: in situ $T$ and $S$ profiles, satellite altimeter SLAs and satellite SSTs. Each is described below. The ARIVO climatology used as first guess for product generation is also described, as well as the Scripps monthly gridded fields which are used for an intercomparison exercise.

\subsection{In situ $T / S$ profiles}

Historical $T$ and $S$ profiles are first used to compute the statistics that relate the surface to subsurface fields. The historical dataset has been constructed using all $T$ and $S$ profiles available in the EN3 dataset (Ingleby and Huddleston, 2007; http://www.metoffice.gov.uk/hadobs/en3/), except those labeled as Argo floats. This historical dataset has then been supplemented with the Argo float observations available at the Coriolis Global Data Acquisition Center as of February 2009 (http://www.coriolis.eu.org). It covers the 1950 to 2008 time period. As this dataset is used to compute the statistics that relate the surface fields (SLA and SST) to subsurface fields, only profiles containing both temperature and salinity (used to calculate a dynamic height) and valid up to a depth of $1500 \mathrm{~m}$ are selected to give a total of 357445 profiles.

$T / S$ profiles from another dataset (CORA3.1) are then used for combining with the synthetic fields or for validation of the synthetic estimates. This comes from the Coriolis data center which is the MyOcean TAC for in situ observations. It includes Argo floats, XBT, CTD and mooring profiles for the period 1993 to 2009 (Cabanes et al., 2011, 2012).

\subsection{Gridded maps of altimeter sea level anomalies}

The altimeter data used are from the SSALTO/DUACS center which is the MyOcean TAC for satellite sea level observations. They consist of gridded SLA products obtained from an optimal combination of all available satellite altimeters (AVISO, 2012). The delayed-mode version of the product is used. These maps are available every 7 days (Wednesdayonly fields) on a $1 / 3^{\circ}$ Mercator grid and the 1993-2009 time series have been used. 


\subsection{Gridded maps of sea surface temperature observations}

Satellite SST data are from daily Reynolds L4 analyses with a $1 / 4^{\circ}$ horizontal resolution, combining AVHRR, AMSR and in situ observations distributed by the National Climatic Data Center at NOAA (Reynolds et al., 2007). Again, the 1993-2009 time series for the Wednesday fields have been used.

\subsection{ARIVO climatology}

Temperature and salinity monthly fields from the ARIVO climatology are used to compute anomalies of the $T$ and $S$ profiles from climatological monthly means (Gaillard and Charraudeau, 2008). The ARIVO climatology has been computed as part of the Mersea European project, the predecessor of the MyOcean project. It is defined on a $1 / 2^{\circ}$ Mercator horizontal grid, for the first $2000 \mathrm{~m}$ on 151 vertical levels and for the global ocean. It has been computed using an optimal interpolation method and all available in situ $T$ and $S$ profiles for the 2002 to 2007 period. It is thus representative of this period.

\subsection{Gridded temperature and salinity fields from Argo floats}

Gridded temperature and salinity fields from the Scripps Institution of Oceanography are also used as an external solution for validation. These are monthly fields defined on a $1^{\circ}$ horizontal grid from the surface down to 2000 dbar on 58 vertical levels. They are computed using only $\operatorname{Argo} T$ and $S$ profiles and an optimal interpolation method (Roemmich and Gilson, 2009). The fields are available in near real-time from January 2004.

\section{3-D thermohaline fields from satellite observations}

The first step of the method consists in deriving synthetic $T$ and $S$ fields from altimeter and SST observations using a multiple/simple linear regression method and covariances calculated from historical in situ observations. A global description of the statistical relationships between surface and subsurface fields is first performed using in situ observations only (Sect. 3.1). As these statistical relationships are estimated using a dynamic height calculated with a reference level at $1500 \mathrm{~m}$ depth for SLA, preprocessing of altimeter measurements is needed to make them consistent with a dynamic height calculated for the first $1500 \mathrm{~m}$ depth of the ocean. The methodology is presented below (Sect. 3.2). The method is then validated using an independent dataset (Sect. 3.3).

\subsection{Relationship between surface and subsurface fields}

Synthetic $T$ and $S$ fields are first derived from altimeter and SST observations using a multiple/simple linear regression method that are expressed as

$$
\begin{aligned}
T(x, y, z, t) & =\alpha(x, y, z, t) \cdot \operatorname{SLA}^{\prime}(x, y, t) \\
& +\beta(x, y, z, t) \cdot \operatorname{SST}^{\prime}(x, y, t)+\operatorname{Tclim}(x, y, z, t)
\end{aligned}
$$

and

$S(x, y, z, t)=\gamma(x, y, z, t) \cdot \operatorname{SLA}^{\prime}(x, y, t)+\operatorname{Sclim}(x, y, z, t)$,

where SLA ${ }^{\prime}$ and $\mathrm{SST}^{\prime}$ denote anomalies from the ARIVO monthly climatology (see Sect. 2.4); Tclim and Sclim denote the ARIVO monthly fields; and $\alpha, \beta$ and $\gamma$ are the regression coefficients of the SLA and SST onto temperature and of the SLA onto salinity, respectively. They vary with depth, time and geographical location and are expressed as covariances between the variables (only the $z$ variable is given here for clarity):

$$
\begin{aligned}
& \alpha(z)=\frac{\left\langle\mathrm{SST}^{\prime}, \mathrm{SST}^{\prime}\right\rangle \cdot\left\langle\mathrm{SLA}^{\prime}, T^{\prime}(z)\right\rangle-\left\langle\mathrm{SLA}^{\prime}, \mathrm{SST}^{\prime}\right\rangle \cdot\left\langle\mathrm{SST}^{\prime}, T^{\prime}(z)\right\rangle}{\left\langle\mathrm{SLA}^{\prime}, \mathrm{SLA}^{\prime}\right\rangle \cdot\left\langle\mathrm{SST}^{\prime}, \mathrm{SST}^{\prime}\right\rangle-\left\langle\mathrm{SLA}^{\prime}, \mathrm{SST}^{\prime}\right\rangle^{2}}, \\
& \beta(z)=\frac{\left\langle\mathrm{SLA}^{\prime}, \mathrm{SLA}^{\prime}\right\rangle \cdot\left\langle\mathrm{SST}^{\prime}, T^{\prime}(z)\right\rangle-\left\langle\mathrm{SLA}^{\prime}, \mathrm{SST}^{\prime}\right\rangle \cdot\left\langle\mathrm{SLA}^{\prime}, T^{\prime}(z)\right\rangle}{\left\langle\mathrm{SLA}^{\prime}, \mathrm{SLA}^{\prime}\right\rangle \cdot\left\langle\mathrm{SST}^{\prime}, \mathrm{SST}^{\prime}\right\rangle-\left\langle\mathrm{SLA}^{\prime}, \mathrm{SST}^{\prime}\right\rangle^{2}}, \\
& \gamma(z)=\frac{\left\langle\mathrm{S}^{\prime}(z), \mathrm{SLA}^{\prime}\right\rangle}{\left\langle\mathrm{SLA}^{\prime}, \mathrm{SLA}^{\prime}\right\rangle} .
\end{aligned}
$$

These covariances are calculated using only in situ observations (the historical dataset described in Sect. 2.1) in order to better describe the relationship that exists for each profile between its surface and subsurface properties. The $T$ observation at the surface is taken for SSTs and dynamic height (DH) calculated using the measured $T$ and $S$ profiles, and a reference level at $1500 \mathrm{~m}$ depth is taken for SLAs.

Covariances are computed locally on a global $1^{\circ}$ horizontal grid using all observations available in a radius of influence around each grid point. This radius of influence is set to $5^{\circ}$ in latitude. In longitude, it starts with a value of $10^{\circ}$ and increases up to $20^{\circ}$ for the annual statistics and up to $25^{\circ}$ for the seasonal statistics to match a minimum number of 500 profiles available for computation of the statistics at each horizontal grid point. The radius of influence is increased in longitude mainly in the tropical Pacific Ocean and in the Southern Ocean (South of $50^{\circ} \mathrm{S}$ ) and to a lesser extent in the tropical Indian and Atlantic Oceans.

Normalized covariances (i.e. correlation coefficients) between dynamic height (DH) and $T$ at $100 \mathrm{~m}$ depth is illustrated in Fig. 1. The horizontal structure of the correlation is large-scale with values higher than 0.6 in most parts of the Indian and Pacific Ocean. Away from western boundary regions, the Atlantic Ocean shows lower values, in the order of 


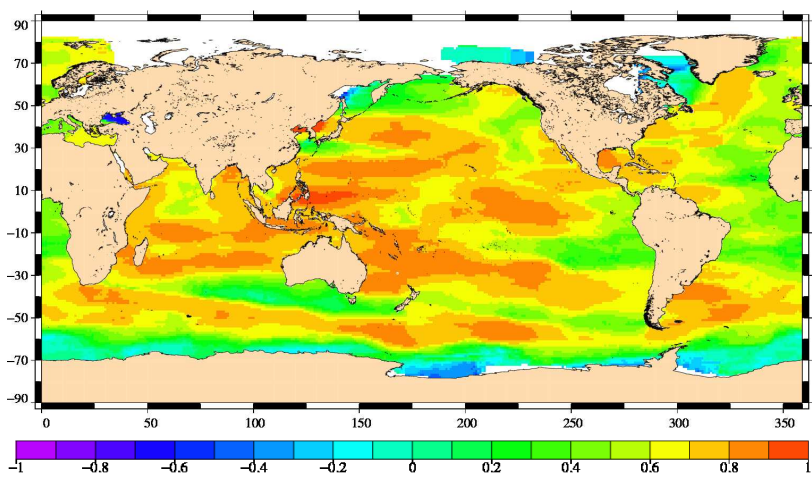

Fig. 1. Annual correlation coefficient between dynamic heights (DH) computed using a reference level at $1500 \mathrm{~m}$ depth and temperature $(T)$ field at $100 \mathrm{~m}$ depth. The color scale ranges from -1 to 1 , every 0.1 .

0.4 to 0.6 . Three latitudinal sections, one in each ocean, have been selected to illustrate the 2-D vertical view of the correlations (Fig. 2). Given the large number of profiles ( $\geq 500)$ used to calculate each correlation coefficient, they are significant within the $95 \%$ confidence level.

DH- $T(z)$ correlation coefficients show very similar structures as a function of latitude and depth for all three oceans (Fig. 2). The mid-latitude regions have values greater than 0.6 below $100 \mathrm{~m}$ and down to $1500 \mathrm{~m}$. In the tropics, the maximum correlation is reached at $100 \mathrm{~m}$ with values of 0.3 to 0.4 elsewhere. Negative values of the order of -0.2 are visible at depths between 800 and $1500 \mathrm{~m}$ around $20^{\circ} \mathrm{S}$ in the Atlantic Ocean, $10^{\circ} \mathrm{S}$ in the Indian Ocean and along the Equator in the Pacific Ocean.

DH-S $(z)$ correlation coefficients also show very similar structures as a function of latitude and depth for all three oceans south of $30^{\circ} \mathrm{N}$ (Fig. 2). The North Atlantic and North Pacific Oceans have indeed very different structures with very negative values and less than -0.6 for the Pacific Ocean, and positive values of the order of 0.3 to 0.4 in the Atlantic Ocean. In the tropics, the three oceans show negative values from the surface down to $100 \mathrm{~m}$, then positive values down to $600 \mathrm{~m}$ in the Atlantic and Pacific Oceans, and only down to $200 \mathrm{~m}$ in the Indian Ocean. The values are then negative again at greater depths. DH-T $(z)$ and DH-S(z) show well correlated baroclinic structures in the tropics. All three Southern Oceans show a very negative tongue with a value of the order of -0.8 . This tongue is close to $70^{\circ} \mathrm{S}$ next to the surface and varies from $40^{\circ} \mathrm{S}$ to $60^{\circ} \mathrm{S}$ from the Atlantic to the Pacific Oceans. It is again related to what is observed for temperature and should be consistent with the different fronts present in the area.

Correlation coefficients between SST and $T(z)$ are also very similar for the three sections but with slight differences (Fig. 2). Values are maximum at all latitudes in the top $20 \mathrm{~m}$. A vertical tongue of maximum values $(0.5$ to 0.6$)$ is visible

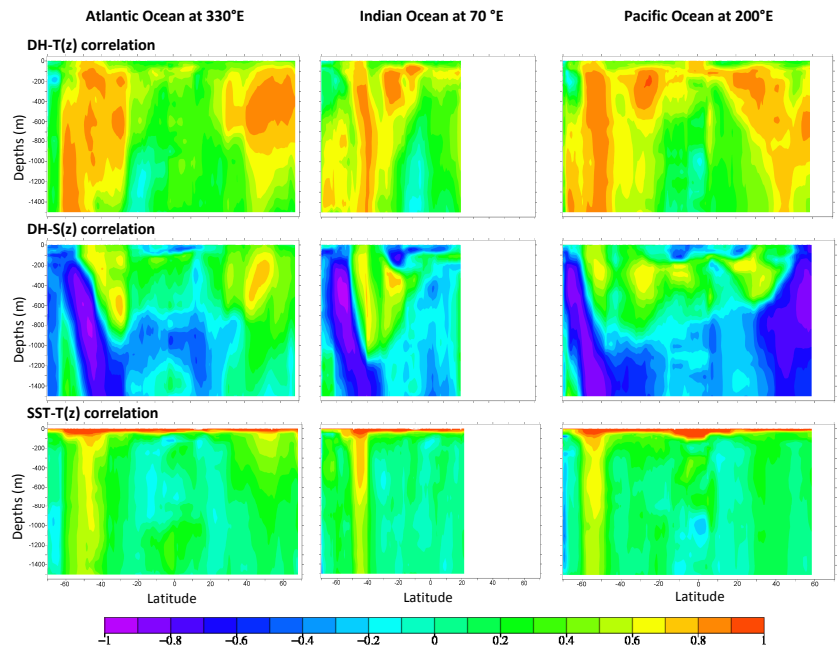

Fig. 2. DH-T(z), DH-S(z) and SST-T $(z)$ annual correlation coefficients for three zonal sections: at $330^{\circ} \mathrm{E}$ in the Atlantic Ocean, at $70^{\circ} \mathrm{E}$ in the Indian Ocean and at $200^{\circ} \mathrm{E}$ in the Pacific Ocean. The latitudes range from $70^{\circ} \mathrm{S}$ to $70^{\circ} \mathrm{N}$ for the Atlantic and Pacific Oceans and from $70^{\circ} \mathrm{S}$ to $30^{\circ} \mathrm{N}$ for the Indian Ocean and the depths from 0 to $-1500 \mathrm{~m}$. The color scale ranges from -1 to 1 , every 0.1 .

for all depths in the three oceans, at $50^{\circ} \mathrm{S}$ in the Atlantic Ocean, at $45^{\circ} \mathrm{S}$ in the Indian Ocean and at $55^{\circ} \mathrm{S}$ in the Pacific Ocean. Most values are elsewhere low and lie between -0.2 and 0.2 .

As the vertical structure of the ocean varies with seasons, seasonal estimates of the covariances are used in the linear regression method. Major differences between seasonal and annual estimates are found for the covariances between SSTs and the vertical thermal structure in direct relation to the variation of the mixed layer depth. High correlations are found down to $400 \mathrm{~m}$ and even down to $1500 \mathrm{~m}$ at mid-latitudes during winter seasons in the Northern and Southern hemispheres where the mixed layer is deepest (Fig. 3). The tropics display small changes between seasons.

\subsection{Pre-processing of altimeter measurements}

As discussed previously, the use of the covariances described in the previous section with observed altimeter SLAs requires preprocessing of altimeter observations to make them consistent with a dynamic height calculated for the first $1500 \mathrm{~m}$ of the ocean.

The differences between a dynamic height calculated using a reference level at $1500 \mathrm{~m}$ and altimeter SLA, assuming negligible measurement errors, represent the circulation at the reference level, or in other words, the deep baroclinic (below $1500 \mathrm{~m}$ ) and barotropic components of the circulation. At $1500 \mathrm{~m}$, the circulation is non-zero and has to be removed from altimeter height before applying the regression. This is obtained here using regression coefficients calculated for the dynamic height anomaly (DHA) computed 


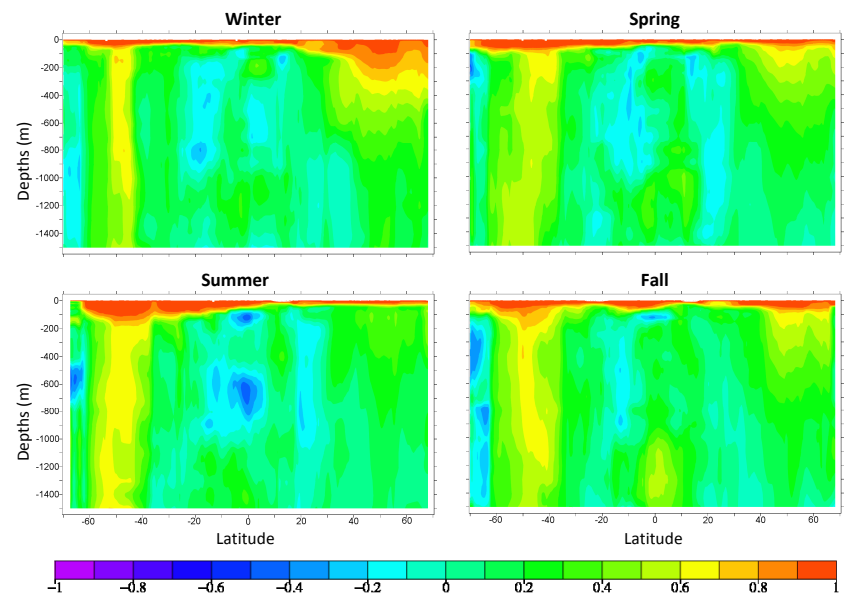

Fig. 3. SST- $T(z)$ correlation coefficients for the Atlantic Ocean zonal section at $330^{\circ} \mathrm{E}$ and for each season. Winter corresponds to Jan/Feb/Mar and so on.

from Argo $T / S$ profiles and a reference level at $1500 \mathrm{~m}$, and the sea level anomaly (SLA) altimeter collocated measurements. The method is very similar to the one described by Guinehut et al. (2006) and Dhomps et al. (2010) except that the reference level is taken at $1500 \mathrm{~m}$.

The spatial structure of the regression coefficient is largely dependent on latitude (Fig. 4). In the equatorial and tropical regions, the vertical structure of the ocean is mainly baroclinic with regression coefficients between SLA and DHA greater than 0.8. Most of the altimeter SLA signal will thus be projected onto the vertical. At mid to high latitudes, the vertical structure of the ocean is more barotropic with regression coefficient from 0.2 to 0.7 , meaning that only 20 to $70 \%$ of the altimeter fields are projected onto the vertical.

Before applying the regression coefficient to each gridded altimeter map, additional preprocessing is needed since altimeter observations are given as anomalies from the 19931999 periods (AVISO, 2012). These anomalies are first recalculated using a 6-yr time mean from 2002 to 2006 to be consistent with the ARIVO climatology (Gaillard and Charraudeau, 2008), which is defined for this 6-yr time period and then used to compute SLAs from the seasonal cycle. Regression coefficients are then applied to each of the gridded altimeter maps to generate the altimeter datasets that will be used for the vertical projection. These fields are hereafter referred to as "steric" SLAs.

\subsection{Comparison with independent datasets}

The effects of the pre-processing of the altimeter measurements as well as the effect of the combination of altimeter and SST observations in deriving synthetic $T$ and $S$ fields are evaluated using independent datasets. Temperature and salinity synthetic fields are first calculated from SLAs, "steric" SLAs (i.e. derived from the regression method described in

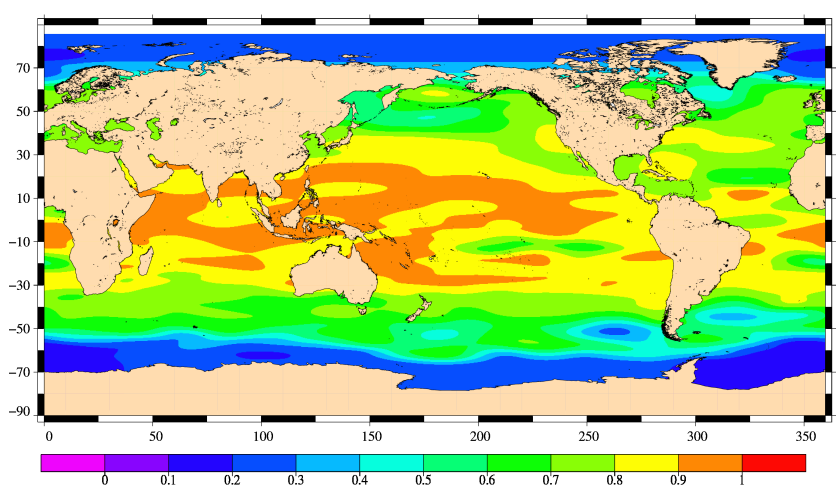

Fig. 4. Regression coefficient between SLA and DHA computed using a $1500 \mathrm{~m}$ depth reference level.

Sect. 3.2) and a combination of "steric" SLAs and SST. They are computed on a $1 / 3^{\circ}$ Mercator horizontal grid, every 7 days (Wednesday-only fields) and from the surface down to $1500 \mathrm{~m}$ on 24 vertical levels. The full 1993 to 2009 period has been processed. As the historical $T$ and $S$ profiles used to compute the covariances cover the 1950 to 2008 period, independent in situ $T$ and $S$ profiles of the year 2009 from the CORA3.1 dataset (see Sect. 2.1) are used to validate the synthetic fields for the year 2009.

The effect of the pre-processing of the altimeter measurements is first assessed by calculating the differences between the independent observations and the reconstructed subsurface $T$ and $S$ synthetic fields using a simple regression method of total and "steric" SLAs and by comparing these differences to the ones calculated from climatological estimates. Synthetic and climatological fields from the ARIVO climatology (see Sect. 2.4) are first interpolated at the time and position of each in situ independent $T$ and $S$ profile. Statistics (mean and rms of the differences) are then calculated from each pair (in situ and synthetic, in situ and ARIVO). Results are illustrated in the Antarctic Circumpolar Current (ACC) region where the circulation at $1500 \mathrm{~m}$ is not negligible (Fig. 4). They show that the pre-processing of the altimeter measurements reduces the rms differences by $5 \%$ at almost all depths for the $T$ fields and up to $10 \%$ for the $S$ fields between 800 and $1300 \mathrm{~m}$ (compare the black and blue curves on Figs. 5 and 6).

For the $T$ field, the additional information provided by satellite SST reduces the rms differences at depth to $900 \mathrm{~m}$ with major effect in the surface and mixed layers. Still in the ACC region, rms of the differences is now about $0.5^{\circ} \mathrm{C}$ at the surface compared to $0.85^{\circ} \mathrm{C}$ when using only altimeter observations and compared to nearly $1{ }^{\circ} \mathrm{C}$ when using climatological estimates.

At the global scale, results indicate additionally that the temperature bias that existed for all depths when using the ARIVO climatology fields is reduced when using the synthetic estimates (Fig. 7). Mean differences are almost zero 

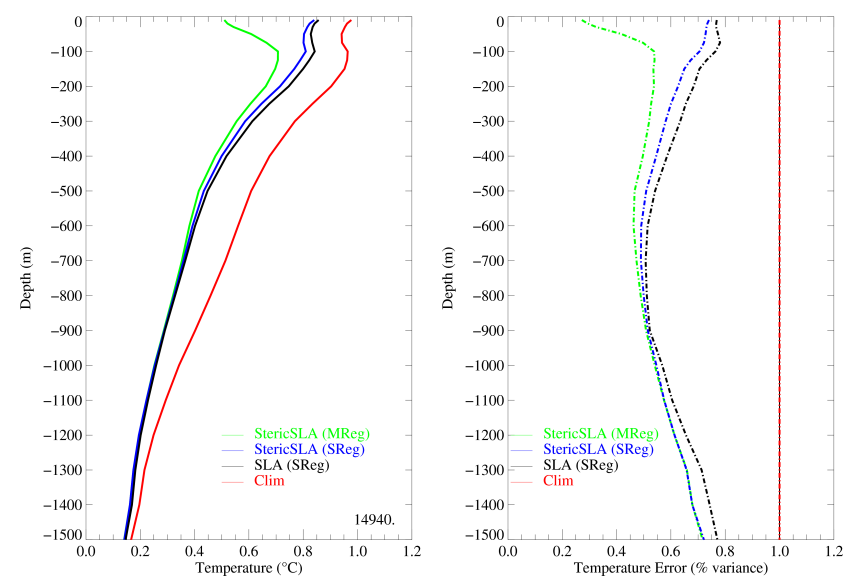

Fig. 5. The rms difference between independent in situ temperature observations and the ARIVO monthly climatology (red) and the synthetic fields: using a simple regression method of total SLA (black) and steric SLA (blue), and using a multiple linear regression method of steric SLA and SST (green). The rms difference as percentage of signal variance (calculated from ARIVO climatology) is shown in right figure. 14900 independent $T$ profiles for year 2009 and located in the ACC have been used for comparison.

for all depths when using the synthetic fields. The rms differences range from $0.5^{\circ} \mathrm{C}$ at the surface, with a maximum of $0.9^{\circ} \mathrm{C}$ in the mixed layer depth decreasing to $0.15^{\circ} \mathrm{C}$ down to $1000 \mathrm{~m}$. Compared to the use of climatological estimates, results indicate that $50 \%$ to $30 \%$ of the temperature fields at depth can be reconstructed from altimeter and SST satellite observations and a statistical method. For salinity, only about $20 \%$ to $30 \%$ of the salinity can be reconstructed from altimeter observations (Fig. 8). Rms differences between the independent observations and subsurface salinity from the synthetic fields are very close to those obtained from the ARIVO fields and range from $0.17 \mathrm{psu}$ at the surface to $0.03 \mathrm{psu}$ at depth.

\section{Combination with in situ $T / S$ profiles}

The second step of the method consists in combining the synthetic estimates with all available in situ $T / S$ profiles using an optimal interpolation method (Bretherton et al., 1976). The method was first developed using simulated data (Guinehut et al., 2004) and is now applied to real observations.

\subsection{Method}

The key issue here is to gain maximum benefit from the qualities of both datasets, namely the accurate information given by the sparse in situ profiles and the mesoscale content provided by the synthetic fields. Le Traon et al. (1998) and Guinehut et al. (2004) have shown that a precise statistical description of the errors in these observations must be intro-
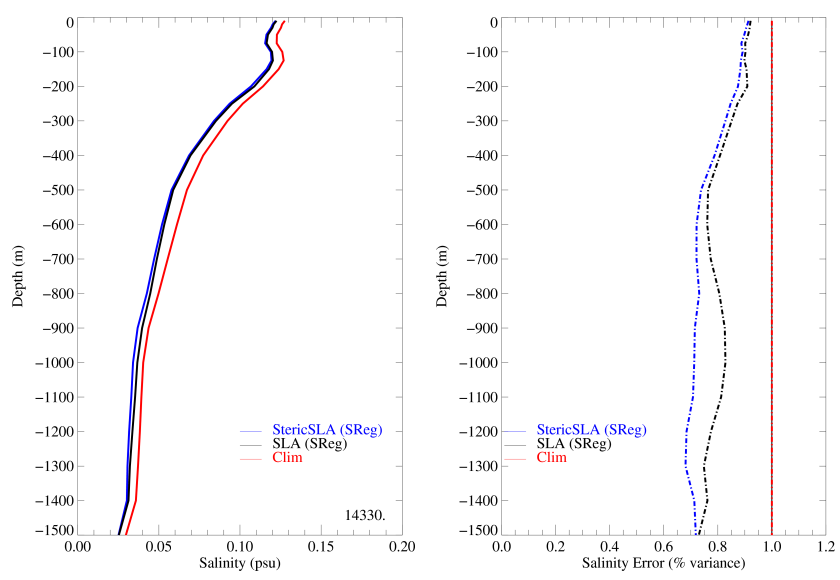

Fig. 6. Same as Fig. 5 but for subsurface salinity. 14300 independent $S$ profiles for year 2009 have been used for comparison.
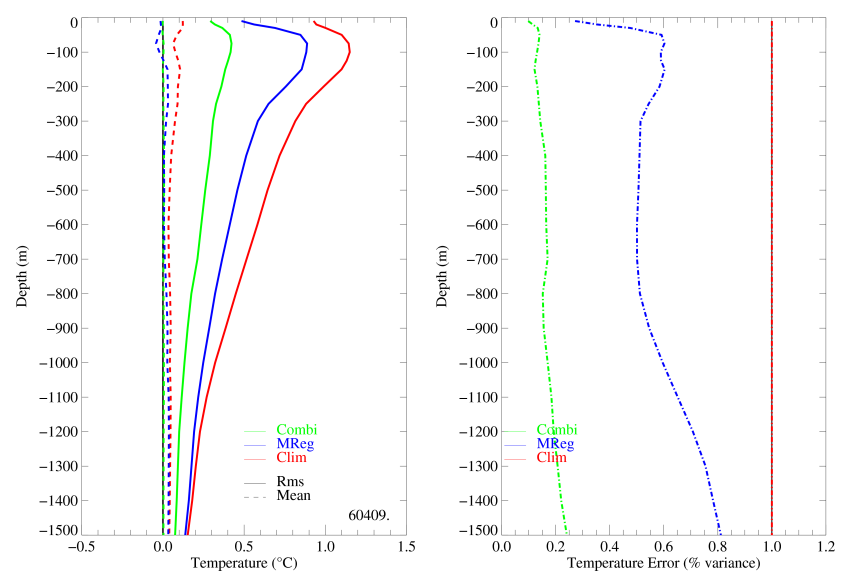

Fig. 7. Mean (dotted line) and rms difference between in situ temperature observations and the ARIVO monthly climatology (red), the synthetic fields (blue) and the combined fields (green). The rms differences as percentage of signal variance (calculated from ARIVO climatology) are also shown in right figure. 60400 independent $T$ profiles for year 2009 have been used for comparison.

duced in the optimal interpolation method. In addition to the conventional use of a measurement white noise representing $10 \%$ of the signal variance, an a priori bias of $20 \%$ and a spatially correlated error of $20 \%$ are also applied to the synthetic fields to correct large-scale errors and bias introduced by the first step of the method (i.e. the regression method). The measurement white noise of $10 \%$ of the signal variance includes both instrument error (expected to be very small) and representation error. Representation error, as defined by Oke and Sakov (2008), is the component of observation error due to unresolved scales and processes. In other words, it is the part of the true signal that cannot be represented on the chosen grid due to limited spatial and temporal resolution. As Oke and Sakov (2008) found values greater than or comparable to measurement error in regions of strong mesoscale variability, 

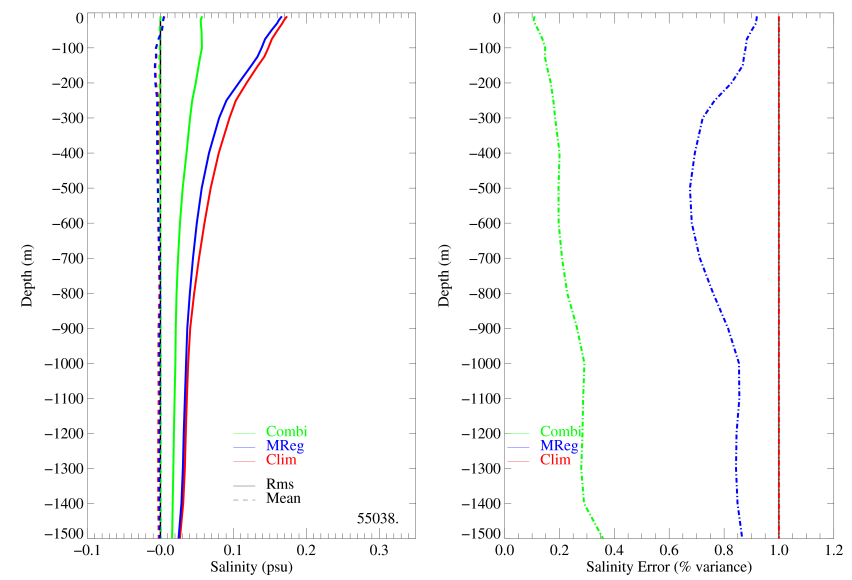

Fig. 8. Same as Fig. 7 but for subsurface S. 55000 independent $S$ profiles of the year 2009 have been used for comparison.

it is applied as a function of signal variance. Furthermore, all the errors used in this study have been estimated empirically and more accurate estimates are left for future studies.

As the main objective of the combination is to correct the large-scale part of the synthetic fields using the surrounding in situ profiles, signal spatial correlation scales are set to twice those used to compute the gridded altimeter maps (AVISO, 2012). They vary from $700 \mathrm{~km}($ resp. $500 \mathrm{~km}$ ) at the Equator to $300 \mathrm{~km}$ north of $60^{\circ} \mathrm{N}$ in the zonal (resp. meridional) directions. The temporal correlation scale is fixed at 15 days everywhere. The signal space-time correlation function is the same as that used in Guinehut et al. (2004). An example of the input and output fields is given in Fig. 9 for the 4th of July 2007. Owing to the mesoscale structures available in the altimeter and SST fields, the synthetic estimate shows mesoscale structures in most parts of the ocean with $T$ anomalies ranging from -5 to $5{ }^{\circ} \mathrm{C}$ at $100 \mathrm{~m}$ (Fig. 9c). The combination of the synthetic estimates with all available in situ $T$ allows correction of the field in some regions such as the North-East Indian Ocean where the in situ $T$ are much colder than the synthetic ones, revealing a shallower thermocline. Amplitudes of the combined fields are thus more similar to the in situ observations but still resolve small-scale structures (Fig. 9e). Furthermore, the combined fields allow resolution of much smaller-scale structures than those obtained by an in situ-only field computed using all in situ observations available and an optimal interpolation method (compare Fig. 9e and 9f).

As with the synthetic fields, the combined estimates are computed on a $1 / 3^{\circ}$ Mercator horizontal grid, every 7 days (Wednesday-only fields) and from the surface down to $1500 \mathrm{~m}$ on 24 vertical levels. The full 1993 to 2009 period has been processed using the in situ $T$ and $S$ profiles from the CORA3.1 dataset described in Sect. 2.1. In situ $T$ and $S$ profiles for year 2009 are also used (as for the synthetic fields; see Sect. 4.2) to validate the combined fields for year
2009. As these comparisons are not independent, the objective here is to check the ability of the combination method to accurately merge the two types of observations. As the in situ observations are used to correct the large-scale structure of the synthetic fields, zero differences are not expected.

Results show that the very small residual mean difference found in the synthetic temperature fields has now disappeared (Fig. 7). The rms difference is reduced for all depths but mainly in the 100-300 m depth layers where the effect of the in situ observations is mostly to correct the depth of the mixed layer. This is true for the global ocean but major effects are observed in the tropics (Fig. 9). Residual rms difference with in situ profiles range from $0.3^{\circ} \mathrm{C}$ at the surface with a slight maximum of $0.42^{\circ} \mathrm{C}$ at $50 \mathrm{~m}$ and down to less than $0.1^{\circ} \mathrm{C}$ below $1000 \mathrm{~m}$. Results are improved by more than $20 \%$ (to $40 \%$ at depth) compared to the use of synthetic estimates alone. For salinity, as only a small part of the signal can be reconstructed from altimeter observations, the in situ profiles reduce the residual difference by more than $40 \%$ for all depths. This result already shows that the in situ observing system and particularly the Argo floats with their global coverage are essential for salinity field estimates.

Independent comparisons (not shown) with a subset of in situ $T$ and $S$ profiles allowed us to estimate more precisely the contribution of the in situ observing system to the 3-D thermohaline fields reconstruction. In situ observations allow the gridded reconstructed subsurface $\mathrm{T}$ fields to be closer to independent observations by at least $5 \%$ at depth and $20 \%$ in the mixed layer depth and near the surface. The main contribution is for the surface salinity field where the differences from independent observations are decreased by $30 \%$. The gain is also visible at depth with an improvement of about $10 \%$.

\subsection{Towards a better restitution of large-scale signals}

The merging method developed here greatly improves the climatological first guess and provides a much better estimate of the $T$ and $S$ fields at high temporal and spatial resolution than that obtainable using in situ observations only. Another example is given in Fig. 10 along the path of a cruise in June 2008 in the North Atlantic Ocean between Portugal and Greenland as part of the OVIDE project (Lherminier et al., 2007). The in situ-only estimate computed using all in situ profiles available in the neighborhood of the cruise path, except those taken during the cruise, allow reconstruction of the very large-scale structure along the section. The mesoscale structures present in the satellite fields (altimeter and SST) allow a much better reconstruction of the mesoscale structures but with a smoother shape (synthetic and combined fields).

Nevertheless, as already demonstrated using simulated observations (Guinehut et al., 2004), the reduction of aliasing due to the mesoscale variability should be instrumental in reconstructing the large-scale and low-frequency part of the 

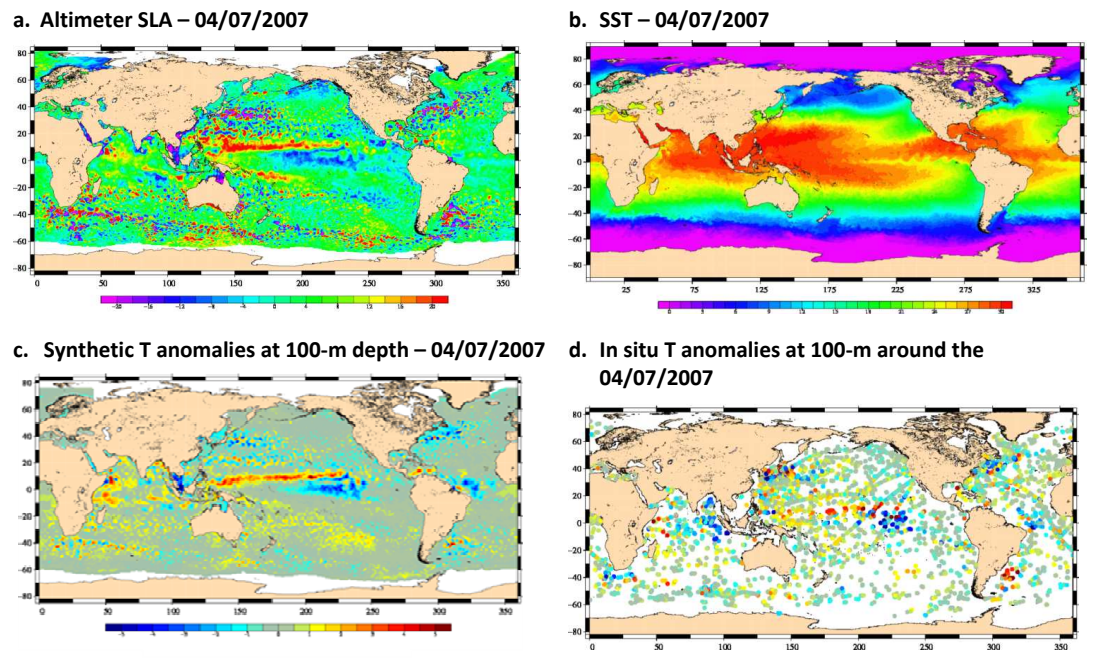

e. Combined T anomalies at $100-\mathrm{m}$ depth 04/07/2007

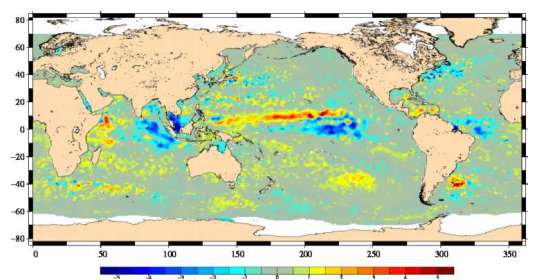

f. In situ only T anomaly at 100-m depth $04 / 07 / 2007$

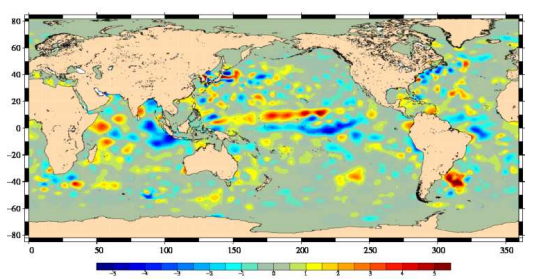

Fig. 9. Input and outputs from the GOOP system for the 4th of July 2007: (a) altimeter SLA (in cm), (b) SST (in ${ }^{\circ} \mathrm{C}$ ), (c) synthetic $T$ anomalies at $100 \mathrm{~m}$ (in ${ }^{\circ} \mathrm{C}$ ), (d) individual in situ $T$ observations at $100 \mathrm{~m}$ (in ${ }^{\circ} \mathrm{C}$ ), (e) combined $T$ anomalies at $100 \mathrm{~m}$ (in ${ }^{\circ} \mathrm{C}$ ). An in situ-only solution for the $T$ anomaly at $100 \mathrm{~m}$ is also displayed in (f) (in ${ }^{\circ} \mathrm{C}$ ).

a. OVIDE 2008 cruise

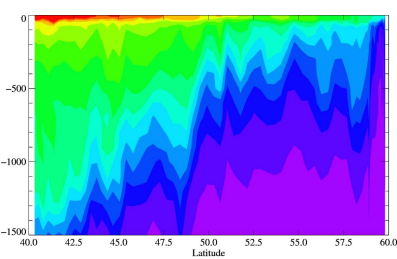

c. Synthetic field

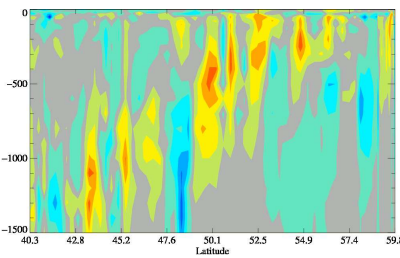

$-2.600 \quad-1.800 \quad-1.000 \quad-0.200$ b. In situ only estimate

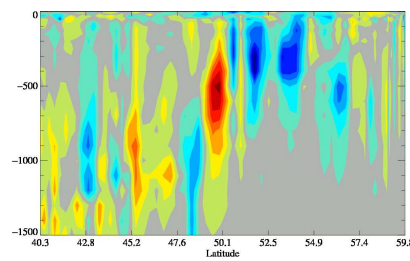

d. Combined field

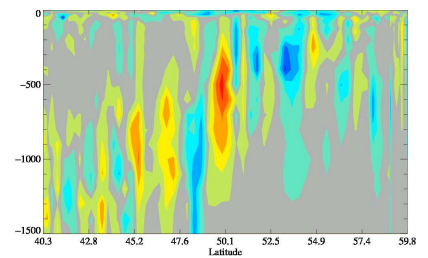

2.200

Fig. 10. Temperature field from the OVIDE 2008 section (a) and as anomalies from the OVIDE 2008 section: (b) in situ-only estimate, (c) synthetic fields and (d) combined fields (in ${ }^{\circ} \mathrm{C}$ ). Note that observations from the OVIDE section have not been used to compute the in situ-only estimate and the combined estimate.

fields. This has been verified using four realizations of the OVIDE cruise (years 2002, 2004, 2006 and 2008). For each of the cruises, the in situ $T$ and $S$ sections are compared to reconstructed fields using only in situ observations and from the combined method. For both estimates the in situ profiles from the cruises are naturally not used. This is done for the instantaneous fields and also for the large-scale part of the fields (scales larger than $400 \mathrm{~km}$ ). From the 365 profiles measured during the four OVIDE cruises, and for the $T$ and $S$ fields, the improvement in reconstructing instantaneous fields is about $30 \%$ of the signal variance using the combined estimates compared to an in situ solution, and this improvement increases to $50 \%$ for the large-scale part of the field. This result is obtained using a small number of in situ independent profiles but it clearly demonstrates that a better reconstruction of the mesoscale structures is required for the reconstruction of the large-scale part of the signal.

\section{Interannual variability reconstructed from the 3-D thermohaline fields}

The interannual variability reconstructed by the observationbased fields will now be examined. Yearly zonal averages of the synthetic and combined fields of anomalies from the 2004 


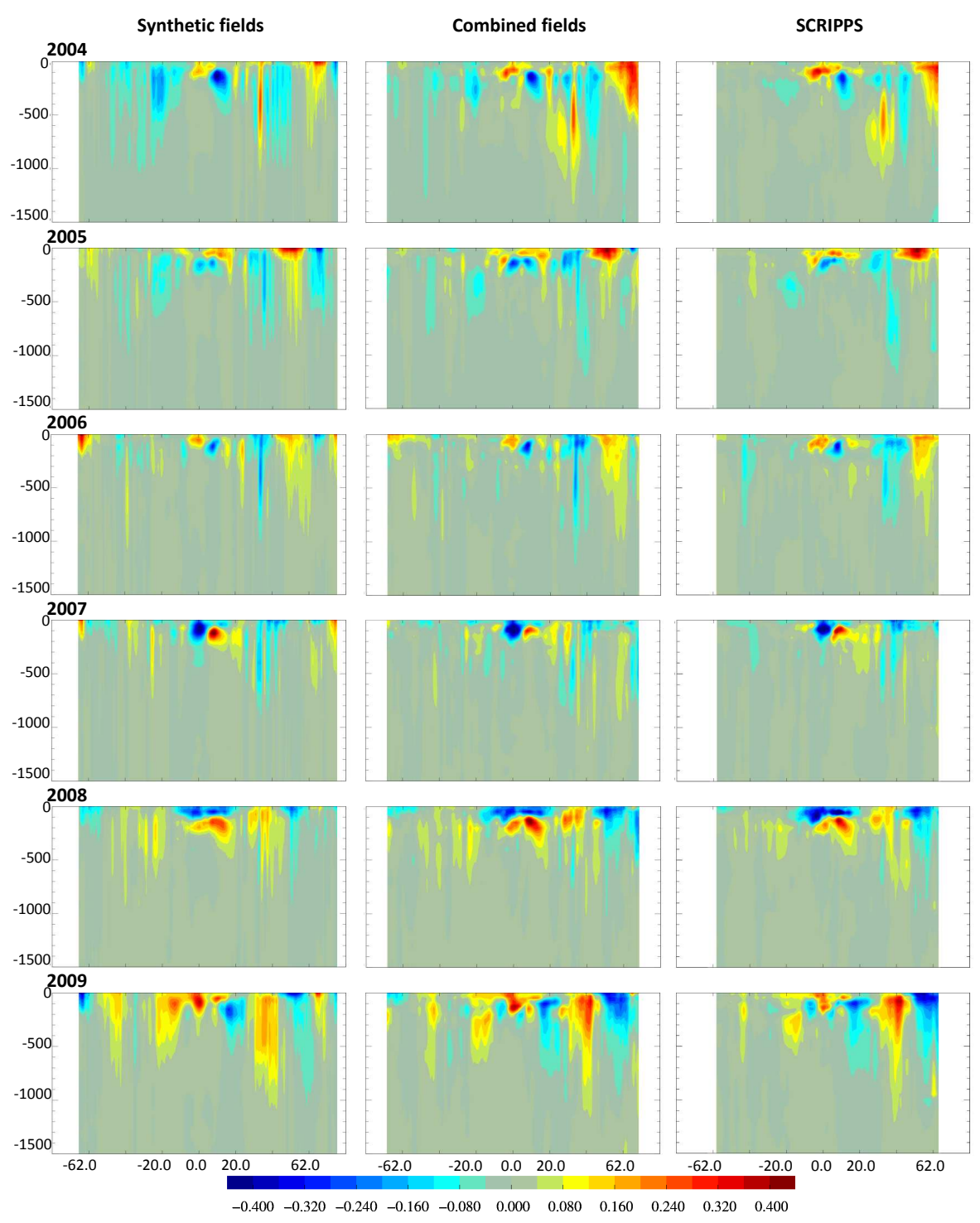

Fig. 11. Yearly zonal averages of the synthetic, combined and SCRIPPS temperatures as anomalies from the 2004 to 2009 periods (in ${ }^{\circ} \mathrm{C}$ ). The latitudinal extents of each field are slightly different.

to 2009 periods are first compared to the SCRIPPS independent estimate (Roemmich and Gilson, 2009; see Sect. 2.5).

For the temperature field, results are very similar in terms of amplitude and geographical position for the synthetic, combined and SCRIPPS estimates (Fig. 11). The signals vary from $-0.4{ }^{\circ} \mathrm{C}$ to $+0.4^{\circ} \mathrm{C}$ with very clear and strong year to year baroclinic variability at the Equator. These strong signals are confined to the top $200 \mathrm{~m}$ and are mainly driven by the successive El Niño/La Niña events. While the Pacific Ocean plays a major role in the global mean, the Indian, and to a lesser extent the Atlantic Oceans also show strong baroclinic equatorial variability. At mid to high latitudes, the amplitudes of the signals are smaller (from $-0.2{ }^{\circ} \mathrm{C}$ to $+0.2^{\circ} \mathrm{C}$ ) but their structure is vertically coherent down to $1000 \mathrm{~m}$ and even deeper between $40^{\circ} \mathrm{N}$ and $50^{\circ} \mathrm{N}$ in the Atlantic Ocean.
Since the year to year variability in the Southern Ocean is not positioned at the same latitude in all three oceans, the global mean shows very low amplitude signals $\left(<0.05^{\circ} \mathrm{C}\right)$ for the 2004 to 2009 periods. Those signals are very consistent with that described in von Schuckmann et al. (2009), who provide a global description of large-scale temperature signals for the period 2003 to 2008. Satellite observations such as SLA and SST combined with a statistical description of the vertical structure of the ocean are thus able to reconstruct the interannual variability patterns of the 3-D temperature field. No bias or spurious signals are introduced by the method. The variability of the 1993 to 2000 periods, which suffer from poor in situ measurement coverage (see among others Roemmich and Gilson, 2009), could now be studied (see below). 


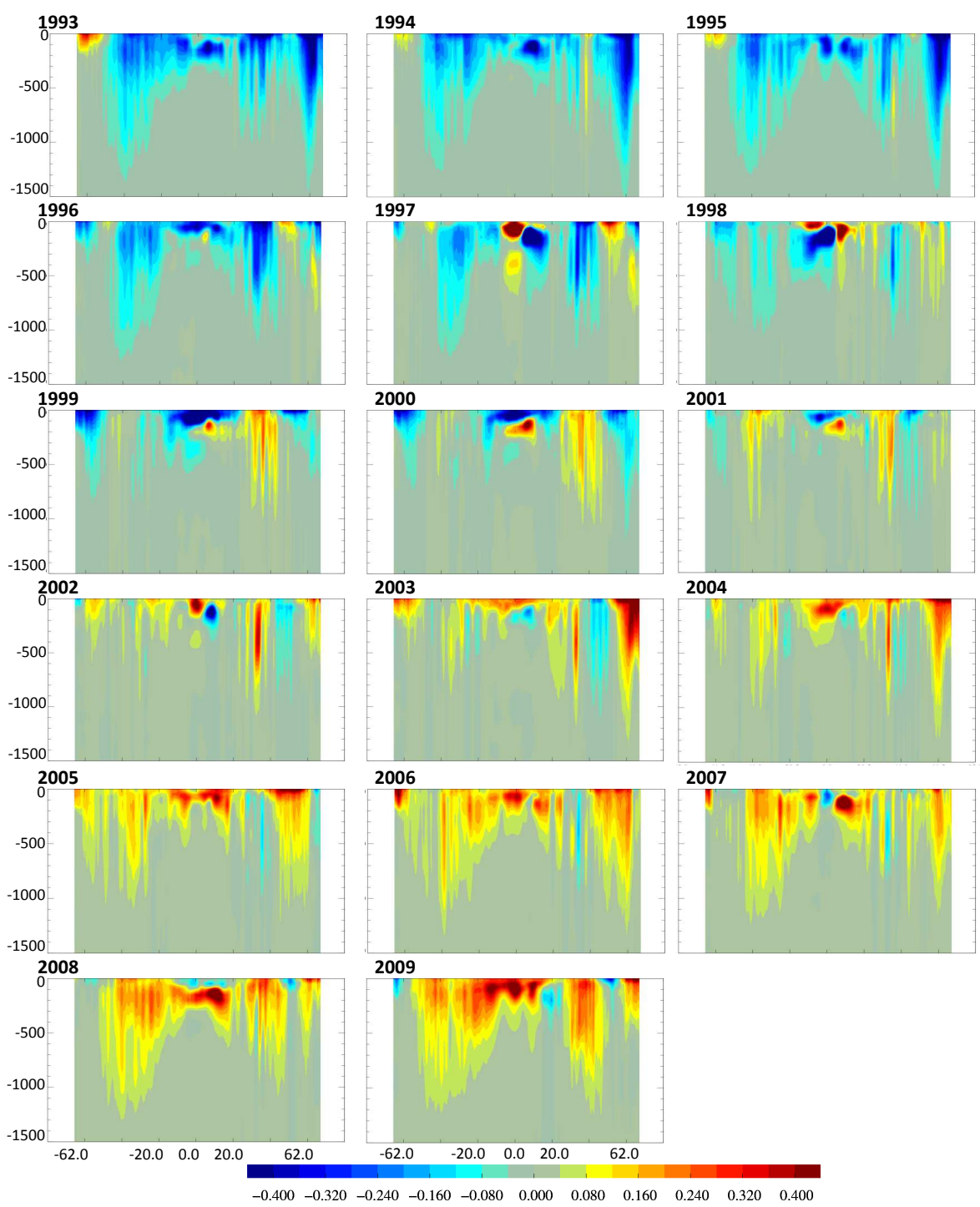

Fig. 12. Yearly zonal averages of the combined temperatures of anomalies from the 1993 to 2009 periods (in ${ }^{\circ} \mathrm{C}$ ).

The picture is nevertheless significantly different for the salinity field since the synthetic estimates are completely unable to reproduce any interannual variability (not shown). This result confirms the fact that the in situ Argo observing system is absolutely essential for salinity. For the combined and SCRIPPS estimates, the signals are very similar and vary between -0.05 and $+0.05 \mathrm{psu}$. They again show very clear and strong interannual variability at the Equator that is generally correlated to that which is observed for temperature. At mid to high latitudes, the global mean signals show a small scale pattern limited mainly to the first $500 \mathrm{~m}$. Again, results are very different between the three oceans. The Atlantic Ocean shows deep vertically coherent structures as far as $1500 \mathrm{~m}$ around $40^{\circ} \mathrm{N}$ and to $1000 \mathrm{~m}$ around $30^{\circ} \mathrm{S}$ with a value of the order of $0.02 \mathrm{psu}$ at depth. The vertical extent of the signals in the Indian and Pacific Oceans is limited to the first $500 \mathrm{~m}$ and the signal amplitudes are also smaller (see also von Schuckmann et al., 2009). Unlike the temperature field, the observation-based method presented here is unfortunately of no help in describing the interannual variability of the salinity field for the years before Argo.

The temperature variability of the $17 \mathrm{yr}$ from 1993 to 2009 can now be qualitatively described using the combined fields. The objective is to illustrate the capability of the method and further analysis will be needed to understand the observed signals and relate them to some forcing mechanisms. This is left for future study. Results are again presented as global zonal averages and as anomalies from the full period. While results vary between the three oceans, clear trends can be extracted from the global means. As for the 2004 to 2009 periods, the amplitude of the signals varies between $-0.4^{\circ} \mathrm{C}$ and $+0.4{ }^{\circ} \mathrm{C}$ with maximum values up to $1.2^{\circ} \mathrm{C}$. Again, strong 
interannual baroclinic variability is found in the equatorial region with a succession of deepening and outcrop of the main thermocline. A clear long term warming is visible in the Southern Ocean of up to $0.8^{\circ} \mathrm{C}$ for the 1993 to 2009 period with a signature down to $1300 \mathrm{~m}$. The warming is not limited to the southern part of the Southern Ocean but is clearly visible at all latitudes between $50^{\circ} \mathrm{S}$ and $20^{\circ} \mathrm{S}$. Rather than a long term trend, a succession of warming and cooling events is visible further south. The variability of the Northern Hemisphere is much more complex at the global scale, with a succession of warming and cooling events at mid and high latitudes revealing the necessity to study more precisely what is occurring separately in the Atlantic and Pacific Oceans.

\section{Conclusions and perspectives}

To understand, monitor and predict the ocean state, Global Ocean Observation-based Products (GOOP) combining satellite and in situ measurements have been developed. Global instantaneous 3-D thermohaline fields are thus generated on a $1 / 3^{\circ}$ Mercator horizontal grid, every 7 days and from the surface down to $1500 \mathrm{~m}$ depth. Near-real-time products are available and the full 1993 to 2009 period has been processed. The main contribution of this study is, however, to show that the accurate but sparse in situ $T / S$ profile observations can be effectively merged with the lower accuracy, but high-resolution, synthetic data derived from satellite altimeter and sea surface temperature observations. This merging provides a much better estimate of the instantaneous, but also large-scale and low-frequency, 3-D temperature and salinity fields as compared with estimates computed using only in situ observations. It has been shown that the reduction of aliasing due to the mesoscale variability is a necessary step for reconstruction of the large-scale and low-frequency part of the fields. This had been demonstrated using simulated observations (Guinehut et al., 2004) and is confirmed here using real observations.

Hydrographic variability patterns for the temperature field, over the 1993 to 2009 period and for the global ocean show that most of the Southern Ocean is dominated by a clear long term warming and that the equatorial regions and the Northern Hemisphere are dominated by interannual to decadal variability. The observed signals have been qualitatively described and regional analyses are needed to better understand them and relate them to different forcing mechanisms. This is left for future study. The description of the temperature variability pattern for the years prior to the Argo era has only been made possible by the statistical relationships between surface and subsurface fields computed using only in situ observations, and mainly observations of Argo profiling floats. Argo has thus indirectly helped the description of the variability of the 1993 to 2000 period. It is, however, much more difficult to infer the vertical structure of the salinity field from satellite SLA observations and a statistical description of the vertical structure of the ocean. This result shows that the in situ observing system and the Argo profiling floats are essential for salinity estimates. New satellite missions measuring Sea Surface Salinity (SSS) as SMOS and Aquarius (Font et al., 2010; Reul et al., 2011) should further help in reconstructing subsurface fields.

The observation-based approach developed here provides an improved and more complete estimate of the state of the ocean compared with estimates based on in situ or satellite observations only. It is also very consistent and very complementary to that provided by ocean reanalysis combining model and observations through an assimilation method (Stammer et al., 2010). Other reprocessing and reanalysis will be available from the European MyOcean I and II projects (Ferry et al., 2010; Haines et al., 2012; Storto et al., 2012). The robustness of the different solutions among statistical methods and observations, models and assimilation systems should be further studied to learn more about the contribution of the different observing systems (Oke et al., 2009,2010 ), the physics of the model, and the effect of the forcing fields (Garric et al., 2011) and the assimilation system. This is a necessary step for Ocean Climate Monitoring studies.

Only thermohaline fields are presented here, but the Global Ocean Observation-based Products also include 3D geostrophic velocity estimates that are calculated using the thermal wind equation combined with absolute surface altimeter geostrophic currents (Mulet et al., 2012). First attempts to compute vertical velocities from our observationbased products were carried out as part of the EU MyOcean MESCLA R\&D project (Buongiorno Nardelli et al., 2012) and open a new era for Ocean Climate Monitoring studies, including vertical exchanges associated with mesoscale activity and their relation to biological processes. This work is a first step towards integrating climate-relevant global ocean datasets such as in situ temperature and salinity profiles, and satellite altimeter and sea surface temperature, and will be continued towards the restitution of higher resolution products.

Acknowledgements. This work was carried out within the scope of the MyOcean project (Development and pre-operational validation of GMES Marine Core Services; 2009-2012) and was funded within the call for proposal EU FP7-SPACE-2007-1 (Grant Agreement nr. 218812) and with support from CNES under contract $82394 / 00$.

Edited by: P. Brasseur 


\section{References}

AVISO: SSALTO/DUACS User Handbook: (M)SLA and (M)ADT near-real time and delayed time products, SALP-MU-P-EA21065-CLS Edn. 2.9, 73 pp., 2012.

Buongiorno Nardelli, B., Guinehut, S., Pascual, A., Drillet, Y., Ruiz, S., and Mulet, S.: Towards high resolution mapping of 3-D mesoscale dynamics from observations: preliminary comparison of retrieval techniques and models within MESCLA project, Ocean Sci. Discuss., 9, 1045-1083, doi:10.5194/osd-91045-2012, 2012.

Bretherton, F. P., Davis, R. E., and Fandry, C. B.,: A technique for objective analysis and design of oceanographic experiments applied to MODE-73, Deep-Sea Res., 23, 559-582, 1976.

Cabanes, C., Grouazel, A., Coatanoan, C., and Turpin, V.,: Coriolis Ocean database for ReAnalysis - CORA3 Documentation, ed. $1.0,50 \mathrm{pp}$. available at: http://www.coriolis.eu.org/Science/ Data-and-Products/CORA-Documentation, 2011.

Cabanes, C., Grouazel, A., von Schuckmann, K., Hamon, M., Turpin, V., Coatanoan, C., Guinehut, S., Boone, C., Ferry, N., Reverdin, G., Pouliquen, S., and Le Traon, P.-Y.: The CORA dataset: validation and diagnostics of ocean temperature and salinity in situ measurements, Ocean Sci. Discuss., 9, 12731312, doi:10.5194/osd-9-1273-2012, 2012.

Dhomps, A.-L., Guinehut, S., Le Traon, P.-Y., and Larnicol, G.: A global comparison of Argo and satellite altimetry observations, Ocean Sci., 7, 175-183, doi:10.5194/os-7-175-2011, 2011.

Ferry, N., Parent, L., Garric, G., Barnier, B., Jourdain, N. C., and the Mercator Océan team: Mercator Global Eddy Permitting Ocean Reanalysis GLORYS1V1: Description and Results, Mercator Ocean Quarterly Newsletter \#36, 15-27 January 2010, 2010.

Font J., Camps, A., Borges, A., Martín-Neira, M., Boutin, J., Reul, N., Kerr, Y. H., Hahne, A., and Mecklenburg, S.: SMOS: The Challenging Sea Surface Salinity Measurement from Space, P. IEEE, 98, 5649-5665, 2010.

Fox, D. N., Teague, W. J., Barron, C. N., Carnes, M. R., and Lee, C. M.: The Modula Ocean Data Assimilation System (MODAS), J. Atmos. Ocean. Tech., 19, 240-252, 2002.

Gaillard, F. and Charraudeau, R.: New climatology and statistics over the global Ocean, MERSEA-WP05-CNRS-STR-001-1A., 2008.

Garric, G., Verbrugge, N., and Bricaud, C.: Large-scale ERAInterim radiative and precipitation surface fluxes assessment, correction and application on $1 / 4^{\circ}$ global ocean 1989-2009 hindcats, EGU General Assembly 2011, Vienna, Austria, 2011.

Gilson, J., Roemmich, D., Cornuelle, B., and Fu, L.: Relationship of TOPEX/Poseidon altimetric height to steric height and circulation in the North Pacific, J. Geophys. Res., 103, 27947-27966, 1998.

Guinehut, S., Le Traon, P.-Y., Larnicol, G., and Philipps, S.: Combining Argo and remote-sensing data to estimate the ocean threedimensional temperature fields - A first approach based on simulated observations, J. Marine Syst., 46, 85-98, 2004.

Guinehut, S., Le Traon, P.-Y., and Larnicol, G.: What can we learn from Global Altimetry/Hydrography comparisons?, Geophys. Res. Lett, 33, L10604, doi:10.1029/2005GL025551, 2006.

Haines, K., Valdivieso, M., Zuo, H., and Stepanov, V. N.: Transports and budgets in a $1 / 4^{\circ}$ global ocean reanalysis 1989-2010, Ocean Sci., 8, 3330-344, doi:10.5194/os-8-333-2012, 2012.
Ingleby, B. and Huddleston, M.: Quality control of ocean temperature and salinity profiles - historical and real-time data, J. Marine Syst., 65, 158-175, doi:10.1016/j.jmarsys.2005.11.019, 2007.

Larnicol, G., Guinehut, S., Rio, M.-H., Drevillon, M., Faugere, Y., and Nicolas, G.: The Global Observed Ocean Products of the French Mercator project, Proceedings of 15 Years of progress in Radar Altimetry Symposium, ESA Sp. Publ., SP-614, 2006.

Le Traon, P.-Y., Nadal F., and Ducet, N.: An improved mapping method of multisatellite altimeter data, J. Atmos. Ocean. Tech., 15, 522-534, 1998.

Lherminier, P., Mercier, H., Gourcuff, C., Alvarez, M., Bacon, S., and Kermabon, C.: Transports across the 2002 GreenlandPortugal OVIDE section and comparison with 1997, J. Geophys. Res., 112, C07003, doi:10.1029/2006JC003716, 2007.

Locarnini, R. A., Mishonov, A. V., Antonov, J. I., Boyer, T. P., Garcia, H. E., Baranova, O. K., Zweng, M. M., and Johnson, D. R.: World Ocean Atlas 2009, Volume 1: Temperature, edited by: Levitus, S., NOAA Atlas NESDIS 68, US Government Printing Office, Washington DC, 184 pp., 2010.

McCarthy, M. C., Talley, L. D., and Roemmich, D.: Seasonal to interannual variability from expendable bathythermograph and TOPEX/Poseidon altimeter data in the South Pacific subtropical gyre, J. Geophys. Res., 105, 19535-19550, 2000.

Meijers, A. J. S., Bindoff, N. L., and Rintoul, S. R.: Estimating the Four-Dimensional Structure of the Southern Ocean Using Satellite Altimetry, J. Atmos. Ocean. Tech., 28, 548-568, doi:10.1175/2010JTECHO790.1, 2011.

Mulet, S., Rio, M.-H., Mignot, A., Guinehut, S., and Morrow, R.: A new estimate of the global 3-D geostrophic ocean circulation based on satellite data and in situ measurements, Deep-Sea Res. Pt. II, 77, 70-81, doi:10.1016/j.dsr2.2012.04.012, 2012.

Oke, P. R. and Sakov, P.: Representation Error of Oceanic Observations for Data Assimilation, J. Atmos. Ocean. Tech., 25, 10041017, doi:10.1175/2007JTECHO558.1, 2008.

Oke, P. R., Balmaseda, M., Benkiran, M., Cummings, J. A., Dombrowsky, E., Fujii, Y., Guinehut, S., Larnicol, G., Le Traon, P.-Y., and Martin, M. J.: Observing System Evaluations using GODAE systems, Oceanography, 22, 144-153, 2009.

Oke, P. R., Balmaseda, M., Benkiran, M., Cummings, J. A., Dombrowsky, E., Fujii, Y., Guinehut, S., Larnicol, G., Le Traon, P.-Y., and Martin, M. J.: Observational requirements of GODAE Systems, in: Proceedings of OceanObs'09: Sustained Ocean Observations and Information for Society (Vol. 2), Venice, Italy, 21-25 September 2009, edited by: Hall, J., Harrison, D. E., and Stammar, D., ESA Publication WPP-306, 2010.

Reul, N., Tenerelli, J., Chapron, B., Vandemark, D., Quilfen, Y., and Kerr, Y. H.: SMOS satellite L-band radiometer: a new capability for ocean surface remote sensing in Hurricanes, J. Geophys. Res., 117, C2, doi:10.1029/2011JC007474, 2011.

Reynolds, R. W., Smith, T. M., Liu, C., Chelton, D. B., Casey, K. S., and Schlax, M. G.: Daily high-resolution blended analyses for sea surface temperature, J. Climate, 20, 5473-5496, 2007.

Roemmich, D. and Gilson, J.: The 2004-2008 mean and annual cycle of temperature, salinity and steric height in the global ocean from the Argo program, Prog. Oceanogr., 82, 81-100, 2009.

Roemmich, D., Johnson, G. C., Riser, S., Davis, R., Gilson, J., Owens, W. B., and Garzoli, S. L., Schmid, C., and Ignaszewski, M.: The Argo Program: Observing the global oceans with profiling floats, Oceanography, 22, 24-33, 2009. 
Stammer, D., Köhl, A., Awaji, T., Balmaseda, M., Behringer, D., Carton, J., Ferry, N., Fischer, A., Fukumori, I., Giese, B., Haines, K., Harrison, E., Heimbach, P., Kamachi, M., Keppenne, C., Lee, T., Masina, S., Menemenlis, D., Ponte, R., Remy, E., Rienecker, M., Rosati, A., Schrëoter, J., Smith, D., Weaver, A., Wunsch, C., and Xue, Y.: Ocean Information Provided through Ensemble Ocean Syntheses, in: Proceedings of OceanObs'09: Sustained Ocean Observations and Information for Society, edited by: Hall, J., Harrison, D. E., and Stammer, D., Vol. 2, Venice, Italy, 21-25 September 2009, ESA Publication WPP-306, 2010.

Storto, A., Russo, I., and Masina, S.: Interannual response of global ocean hindcasts to a satellite-based correction of precipitation fluxes, Ocean Sci. Discuss., 9, 611-648, doi:10.5194/osd-9-6112012, 2012.
Swart, S., Speich, S., Ansorge, I. J., and Lutjeharms, J. R. E.: An altimetry-based gravest empirical mode south of Africa: 1. Development and validation, J. Geophys. Res., 115, C03002, doi:10.1029/2009JC005299, 2010.

von Schuckmann, K., Gaillard, F., and Le Traon, P.-Y.: Global hydrographic variability patterns during 2003-2008, J. Geophys. Res., 114, C09007, doi:10.1029/2008JC005237, 2009.

Willis, J. K., Roemmich, D., and Cornuelle, B.: Combining altimetric height with broadscale profile data to estimate steric height, heat storage, subsurface temperature, and sea-surface temperature, J. Geophys. Res., 108, 3292, doi:10.1029/2002JC001755, 2003. 